\title{
MOLECULAR CHARACTERIZATION OF INFECTIOUS BURSAL DISEASE VIRUS FROM COMMERCIAL POULTRY IN PAKISTAN
}

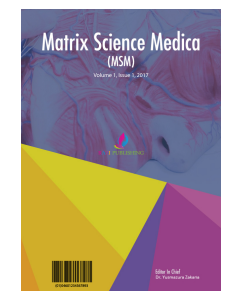

\author{
Rai Shafqat Ali Khan ${ }^{*}$, Mudasser Habib ${ }^{1}$, Muhammad Salah Ud Din Shah' ${ }^{1}$, Waqas Ali ${ }^{1}$, Zaheer Hussain ${ }^{2}$, Zahid Ali Tahir ${ }^{3}$ \\ ${ }^{1}$ Department of Biological Sciences, Vaccine Production Group, Animal Science Division, Nuclear Institute for Agriculture and \\ Biology (NIAB), Pakistan Institute of Engineering and Applied Sciences (PIEAS), Islamabad, Pakistan \\ ${ }^{2}$ Institute of Agricultural Sciences, University of Punjab, Lahore, Pakistan \\ ${ }^{3}$ Poultry Diagnostic Laboratory, Kamalia, Toba. Teck. Singh, Pakistan \\ ${ }^{*}$ Corresponding Author Email: dr.rai.shafqat29@gmail.com
}

This is an open access article distributed under the Creative Commons Attribution License, which permits unrestricted use, distribution, and reproduction in any medium, provided the original work is properly cited.

\begin{tabular}{|c|c|}
\hline ARTICLE DETAILS & ABSTRACT \\
\hline Article history: & Infectious bursal disease (IBD) is an immunosuppressive disease of young, growing chickens which results in \\
\hline Received 12 August 2017 & impaired growth or mortality of rearing flocks. In the current era there is a re-emergence of very virulent Infectious \\
\hline Accepted 12 September 2017 & Bursal Disease Viruses (vvIBDV) and classical variant (cv) IBDV strains which increased the financial losses of poultry \\
\hline Available online 26 October 2017 & $\begin{array}{l}\text { industry worldwide. Recent studies were conducted to characterize the existing vvIBDVs prevailing in Pakistan. The } \\
\text { suspected samples were collected from the field outbreaks during the period from } 2014-2017 \text {. IBDV was detected by }\end{array}$ \\
\hline Keywords: & $\begin{array}{l}\text { RT-PCR. The sequences of VP2 gene (hyper variable region) were determined and available details were aligned with } \\
\text { sequences submitted inGenBank. Phylogenetic analysis reveals that both vvIBDV and classical variant strains were }\end{array}$ \\
\hline Very virulent Infectious Bursal Disease & circulating in different regions of Pakistan. In Indo-Pak isolates, the presence of virulent markers, amino acids (A222, \\
\hline Virus (vvIBDV); reverse transcriptase & I242, Q253, I256 and S299) and "Serine rich- heptapeptide" indicated the presence of very virulent viruses. The \\
\hline Polymerase Chain Reaction (RT-PCR); & presence of T284A isan indicator of vvIBDVs in local poultry farms. More than $99 \%$ similarity of Pakistani isolates \\
\hline $\begin{array}{l}\text { Phylogenetic analysis; commercial } \\
\text { poultry }\end{array}$ & with Indian sequences reflects the trans-boundary spread of IBD. In recent studies amino acid, Glutamine (Q) is \\
\hline & $\begin{array}{l}\text { investigated that Glutamic acid (E) is located at position } 300 \text { in minor hydrophilic region III of VP2 protein in all } \\
\text { reported Pakistani isolates. It is the unique feature of indigenous strains. This study will be useful in understanding } \\
\text { the origin and pathotypes of IBDV circulating in Pakistan. }\end{array}$ \\
\hline
\end{tabular}

\section{INTRODUCTION}

Infectious bursal disease (IBD) is an immunosuppressive viral disease of young, growing chickens, which increase mortality or result in impaired growth of rearing flock [1, 2]. IBDV replicates in Bursa of Fabricius [3] and damages the B-lymphocytes that trigger immunosuppression. Severely infected birds are more prone to secondary infections. Recovered flock show under growth that leads to poor response to vaccines. This virus belongs to family Birnaviridae and genus Avibirnavirus. The IBD Virus is a bi-segmented genome bearing double stranded RNA structure. The larger segment A has two open reading frames; one covers VP5 while other consists of polyprotein, VP2-VP4-VP3. Single protein, VP1 is part of smaller segment B. It plays the role ofRNA dependent RNA polymerase (RdRp) in virus replication [4]. Two serotypes of IBDV are reported; only serotype 1 is responsible for causing disease in chicken. Initially the presence of IBD was reported in 1971 [5]. This disease remained unnoticed till 1987 [6, 7]. The prevalence of this disease in Pakistan was $7.75 \%$ during 2009. Mortality rate and share of IBD is increasing due to variant strains [7]. Under high selection pressure in immune populations there is emergence of new viral strains in targeted poultry flock. VP2, structural protein has a major virus neutralizing conformational epitopes in hypervariable region [8-10]. Antigenicity and virulence of the IBDV has been studied extensively on the genetic basis to control IBD [11-14].

Classical and variant viruses are prevalent worldwide [15-17]. For genotyping of virulent IBDVs, the amino acid residues from 206-350 (hypervariable region) are of key importance in serotype 1 . This range of amino acid includes two major hydrophilic sets, denoted by peak A (210-225) and B(312-324) whereas smaller hydrophilic peaks are present between these major regions [18]. In hypervariable sequence of VP2 gene, four amino acid changes, 222A, 256I, 294I, and 299S have been noted in all European-like vvIBDVs. These molecular markers can be used to differentiate very virulent (vv) IBDVs from classical and variant viruses [19]. The vvIBDVs were first reported in 1987 in Pakistan [6] whereas these were documented in 1992 in Indian flocks. These strains were responsible for field out breaks even in vaccinated flocks [20]. For detection of new strains circulating in various regions of Pakistan, samples from different IBDV infected commercial flocks were collected from 2014 to 2017. After confirmation of isolates, these were sequenced and compared with reported strains of IBDV.

\section{MATERIAL AND METHODS}

\subsection{Source and collection of samples}

IBDV suspected flocks were examined all over Punjab, Pakistan from 2014-2017 and bursal tissues were collected along with complete history of disease. The selected samples were collected from broiler, layer and Golden messari farms. The bursae were stored at $-70 \mathrm{oC}$ in Lab of Nuclear Institute for Agriculture and Biology, Faisalabad, Pakistan maintaining standard conditions [21]. In extreme environmental conditions, samples from far areas were carried in falcon tubes containing phenol-chloroform (5:1), $\mathrm{pH} 4.3 \pm 0.2$ in order to inactivate and preserve the viral genome for further amplification [22]. The isolates collected from entire region of Punjab (Pakistan) were assigned IDs showing year of collection, geographic regions and type of birds.

Table 1: Detail of research isolates and already reported sequences of Pakistan (Only eight sequences reported up till now)

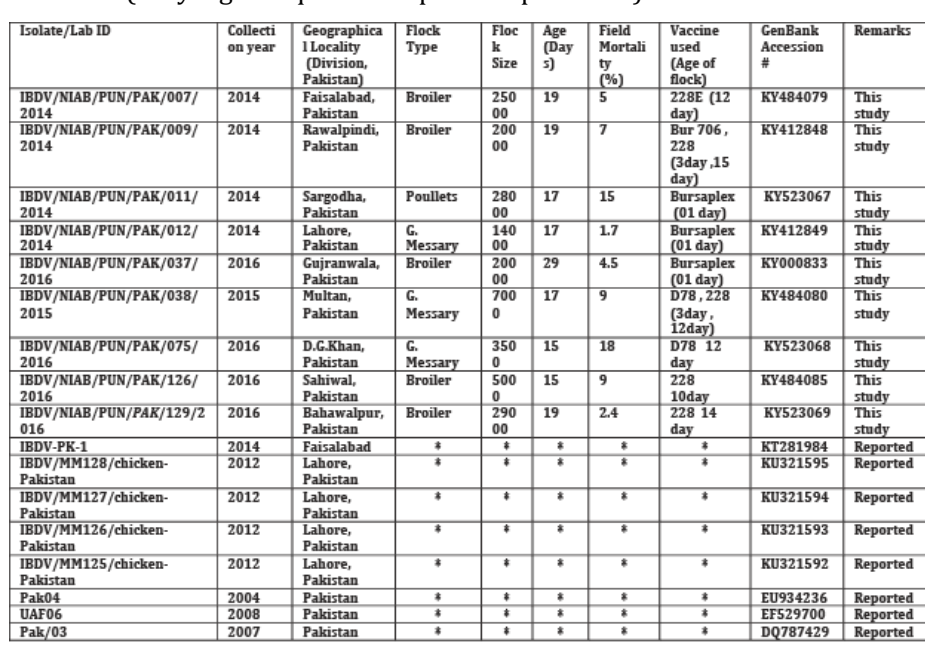

G.Messary stands for Golden Messary (Local Breed) * Information not available 


\subsection{RNA Extraction, cDNA Synthesisand PCR}

RNA was extracted by FavorPrep ${ }^{\circledR}$ viral nucleic acid extraction kit (Favorgen, Biotech Corporation, Taiwan) according to manufacturer's protocol. Total RNA was eluted in $40 \mu \mathrm{L}$ elution buffer. Complimentary DNA (cDNA) was synthesized by using Fermantas Revert Aid First Strand cDNA kit. The extracted RNA $(5 \mu \mathrm{L})$ was heated for $5 \mathrm{~min}$ at 65 oC with 1 $\mu$ LRandom hexamer, chilled on ice and added $08 \mu \mathrm{L}$ reaction mixture containing $4 \mu \mathrm{L}$ of $5 \mathrm{X}$ reaction buffer, $1 \mu \mathrm{LRnase}$ inhibitor, $1 \mu \mathrm{L}$ reverse transcriptase and $2 \mu \mathrm{L}$ of $10 \mathrm{mMdNTPs}$ mix. Then all the mixture was mixed and centrifuge. Initially incubate at $25 \mathrm{oC}$ and then $42 \mathrm{oC}$ for an hour. The reaction was terminated by heating at $70 \mathrm{oC}$ for five minutes. Synthesized cDNA was used as template for polymerase chain reaction (PCR).

Among three pair of primers, two pair of primers were used for studying partial details of VP2 gene and one pair is used for complete sequencing of VP2 gene. The cycling conditions for amplification of PCR product consisted of initial denaturation at $94^{\circ} \mathrm{C}$ for $5 \mathrm{~min}$, followed by 30 cycles of $94^{\circ} \mathrm{C}$ for 30 seconds, annealing at $55^{\circ} \mathrm{C}$ (VP2-f / VP2-r) and $57^{\circ} \mathrm{C}$ (VP-f/VP$r$ and IBD-f/IBD-r) for 30 seconds and extension at $72^{\circ} \mathrm{C}$ for $1 \mathrm{~min}$. After completion of 30 cycles, a final extension at $72^{\circ} \mathrm{C}$ for $10 \mathrm{~min}$ was carried out. The primer pairs VP2-f / VP2-r and VP-f/VP-r produce DNA amplicons of about 460 and 743 base pairs whereas IBD-f/IBD-r amplifies 1377 base pairs, respectively. First two pair of primers were used for initial screening of field isolates. The later one primer was used for complete VP2 gene. The amplified PCR product was visualized under UV light following electrophoresis in the $1.5 \%$ agarose gel stained with Ethidium Bromide [23].

Table 2: Primers used in detection of field isolates

\begin{tabular}{|l|l|c|c|}
\hline \multicolumn{1}{|c|}{$\begin{array}{c}\text { Primer } \\
\text { name }\end{array}$} & \multicolumn{1}{|c|}{ Primer sequence (5'-3') } & $\begin{array}{c}\text { Amplicon } \\
\text { length (bp) }\end{array}$ & Reference \\
\hline $\begin{array}{l}\text { VP2-f } \\
\text { VP2-r }\end{array}$ & $\begin{array}{l}\text { CAGGGTCAGGGCTAATTGTCTTTT } \\
\text { ACTCTGGGCCTGTCACTGCTGTC }\end{array}$ & 460 & This study \\
\hline $\begin{array}{l}\text { VP-f } \\
\text { VP-r }\end{array}$ & $\begin{array}{l}\text { *GCCCAGAGTCTACACCAT } \\
\text { *CCCGGATTATGTCTTTGA }\end{array}$ & 743 & Jackwood DJ (2012) \\
\hline $\begin{array}{l}\text { IBD-f } \\
\text { IBD-r }\end{array}$ & $\begin{array}{l}\text { CGCAGCGATGACAAACCT } \\
\text { GGCACAGCTATCCTCCCTAAG }\end{array}$ & 1377 & This study \\
\hline
\end{tabular}

*VP-f/VP-r primer was reported previously whereas the later were selfdesigned [17].

\subsection{Nucleotide sequencing and phylogenetic analysis of VP2-HVR}

PCR product wasre-amplified and confirmed by gel electrophoresis. ThisPCR product $(50 \mu \mathrm{L})$ was loaded in $1 \%$ gel andband was excised. Then PCR product was purified according to Extractionkit's protocol as described by the manufacturer (Biobasic, USA). The prepared samples were sent to third party (Macrogen/ABI) for sequencing. The products were sequenced with capillary electrophoresis method using ABI PRISM 3730xl Genetic Analyzer developed by Applied Biosystems (ABI), USA. BigDye $®$ Terminator v3.1 Cycle Sequencing kit was used for preparation and further processing of DNA. Nucleotide sequences were assembled and edited by using BioEdit software, version 7.2.1 and 'EditSeq' program of Laser gene software (DNASTAR, Madison, USA). Sequences derivedfrom all the field isolates were edited with the nucleotide sequences from position 576 to 1296 [18]. Deduced amino acid sequences (position 193-432) were aligned by the Clustal $W$ method using the 'BioEdit' program. The sequences were then submitted in the GenBank database for accession numbers. Phylogenetic trees were constructed in MEGA6 using the neighbor joining (N) method with the Kimura three-parameter evolutionary model $[4,24,25]$. The topological reliability of the trees was inferred by the bootstrap method with 1050 replicates. All the sequences were aligned in groups. Already reported sequences of IBDVs were also included in the data for comparison and understanding the circulating field strains.

Phylogenetic tree of reported Pakistani IBDV isolates including novel isolates on the basis of hypervariable region of VP2 gene. For genetic analysis, clusters of various groups categorizing IBDV into very virulent (VV) \{subdivided in VV-1, VV-2 and VV-3\}, classical/ variant and attenuated strains for constructing phylogenetic tree.Red circles-study isolates, green circles-other Pakistani isolates, blue rectangles shows attenuated/vaccinal strains and brown rectangles indicate other reported sequences of different countries in phylogenetic studies. The evolutionary history was inferred using the Neighbor-Joining method [1]. The optimal tree with the sum of branch length $=0.45426469$ is shown. The percentage of replicate trees in which the associated taxa clustered together in the bootstrap test (1050 replicates) are shown next to the branches [2]. The tree is drawn to scale, with branch lengths in the same units as those of the evolutionary distances used to infer the phylogenetic tree. The evolutionary distances were computed using the Tamura 3-parameter method [3] and are in the units of the number of base substitutions per site. The analysis involved 33 nucleotide sequences. Codon positions included were $1 \mathrm{st}+2 \mathrm{nd}+3 \mathrm{rd}+$ Noncoding. All positions containing gaps and missing data were eliminated. There was a total of 429 positions in the final dataset. Evolutionary analyses were conducted in MEGA6 [4].

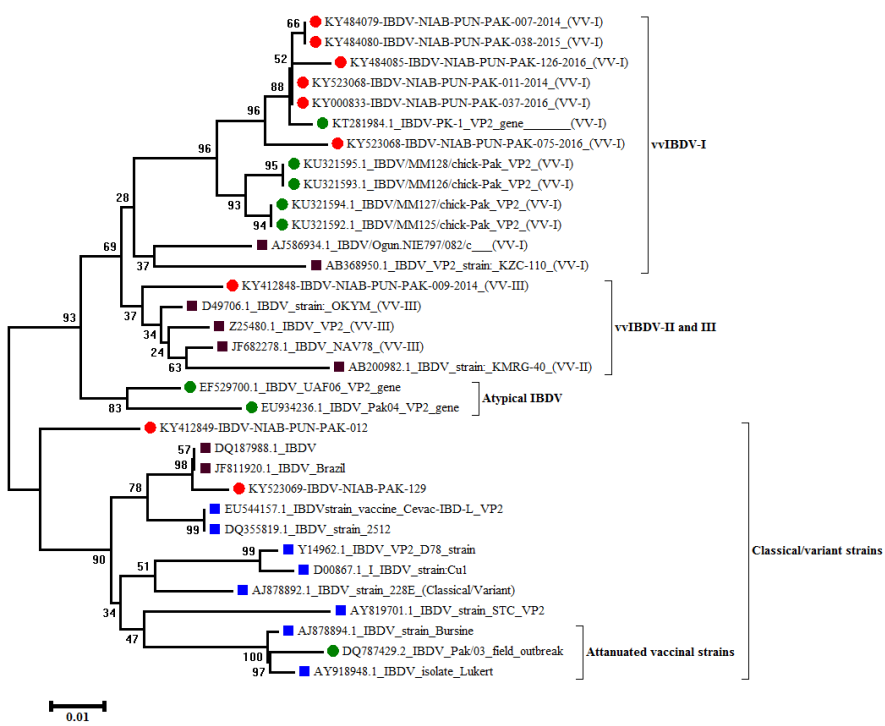

Figure 1: Red circles point to research isolates. Green circles are spots of other Pakistani reported isolates. Blue rectangles show vaccine strains. All remaining black rectangles provide details about reported isolates.

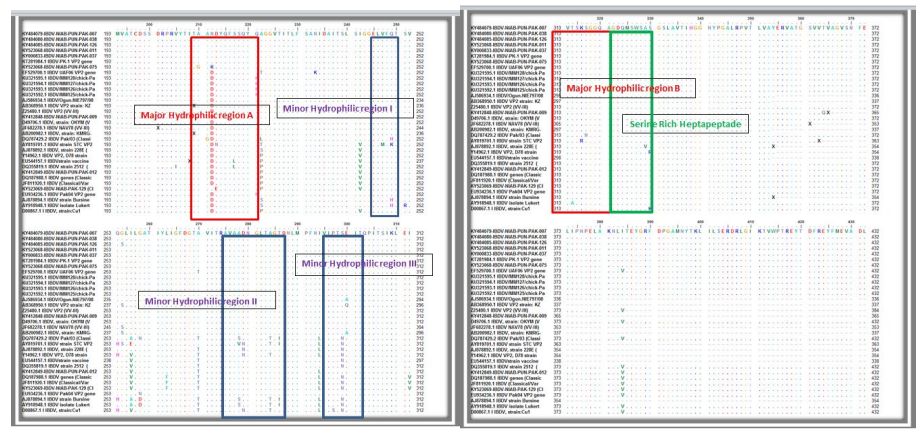

Figure 2: Alignment of deduced amino acid sequences of VP2 gene variable region of different IBDV isolates by the Clustal method with the 'BioEdit' program. Major Hydrophilic regions ' $A$ ' and ' $B$ ' were shown in red boxes. Minor Hydrophilic regions were marked in purple boxes and heptapeptide, Serine rich area enclosed in green box. Amino acid positions in the bottom are as per Bayliss et al. (1990).

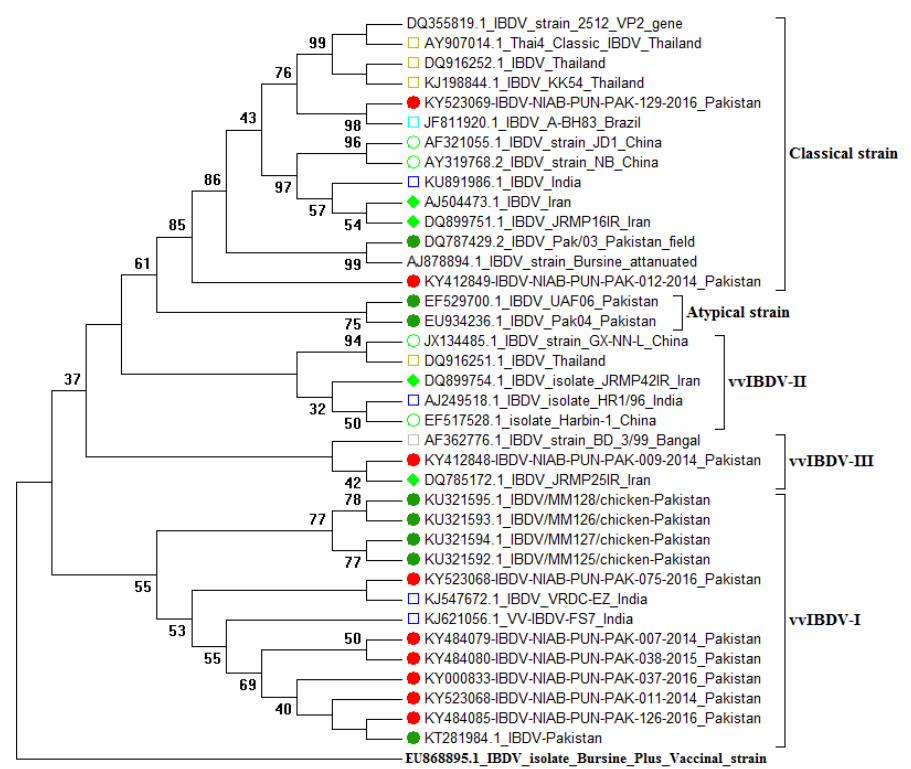

Figure 3: The evolutionary history was inferred using the Neighbor-Joining method [1]. The bootstrap consensus tree inferred from 1050 replicates [2] is taken to represent the evolutionary history of the taxa analyzed [2] Branches corresponding to partitions reproduced in less than $50 \%$ bootstrap replicates are collapsed. The evolutionary distances were computed using the 
Tamura 3-parameter method [3] and are in the units of the number of base substitutions per site. The analysis involved 38 nucleotide sequences. Codon positions included were $1 \mathrm{st}+2 \mathrm{nd}+3 \mathrm{rd}+$ Noncoding. All positions containing gaps and missing data were eliminated. There was a total of 402 positions in the final dataset. Evolutionary analyses were conducted in MEGA6 [4]. Red circles indicate research isolates. Green circles are spots of other Pakistani reported isolates. All remaining symbols provide details about neighboring/boarder sharing countries reported isolates.

\section{RESULTS}

\subsection{Molecular detection of IBDV isolates}

From different poultry farms of Punjab, Pakistan, 130 samples were collected. These suspected IBD samples were tested by RT-PCR. The age of flock ranged from 14 to 35 days. At the time of sample collection, the morbidity fluctuated from 15 to 85 percent while mortality ranges between 1.7 to 18 percent. IBD mainly affects early growing birds, below six weeks of age [26]. The clinical and sub-clinical signs vary widely among diseased flocks. The classic and variant viral strains responsible for outbreaks showed different clinical picture. The severity of infection depends upon virulence of IBDV [27]. On the basis of post mortem findings and clinical signs these can be grouped into three categories. The classical group showed bursal inflammation with hemorrhagesin thigh and breast muscles. It showed moderate mortality whereas variant group infects the flock without typical clinical signs. There is bursal regression with immunosuppression that leads to poor growth [28]. The third group is "vvIBDV". Most of outbreaks were noted due to this strain. It exhibits severe clinical signs with Bursal and muscular hemorrhages. Clinically infected birds are anorexic, listlessness, ruffled feathers, vent pasting, and overall poor appearance [29]. The survived birds showed severe immunosuppression which leads to secondary bacterial and viral infections [27].

Above mentioned primers were used for amplification of desired samples. 63 percent samples were found positive with VP-f/VP-r and VP2-f/VP2-r. These positive samples were further amplified with IBD-f/IBD-r (Complete VP2). The representative sequences of positive sample from each division of province were incorporated in the phylogenetic tree formation. The GenBank accession numbers KY484079, KY412848, KY523067, KY412849, KY000833, KY484080, KY523068, KY484085 and KY523069 representing each division of Punjab, Pakistan.

\subsection{BLAST sequence analysis of VP2 gene}

For analysis of nucleotide and deduced (hvVP2) amino acids, sequences were BLAST in GenBank (www.ncbi.nlm.nih.gov). Punjab Province consists of nine (9) divisions. From all positive samples, sequenced template was selected from each division. It was found that six putative analytes (KY484080, KY484085, KY523068, KY000833 KY484079 and KY523068) show 98 to $99.6 \%$ similarity with IBDV-PK-1, registered in 2014 from Faisalabad division. The remaining sequences reveal less similarity (92.3-95\%) from the reference strain and fall closer to attenuated ones. The isolate from Bahawalpur division (KY523069) pointed its similarity $(97.56 \%)$ with vaccine strain. It relates identity (99\%) with Brazilian's IBDV (JF811920.1). The isolate KY412849 reflects similarity 97\% with Brazilian (JN982271) and Thailand (KJ198844) strains. Among the research isolates more than 66 percent fall close to the Indian strain (KJ547672).

Reported train (KY412848) showed99\% matching with Iranian strain (DQ630452). When Iranian strain was blasted it showed 99\% similarity with Indian sequence (EU788042) bearing ID, IBDV strain VMB/ Karnataka/India/2005. The sequenced stain KY523068 representative of D.G Khan Division co-relates (98\%) with Indian isolate, KJ547673. This Indian isolate is also very close to Pakistani strain (KT281984).

\subsection{Phylogenetic analysis of VP2-HVR}

The sequences of studied isolates were submitted to GenBank and analyzed by phylogenetic tree. The sequenced research samples, attenuated/ vaccinal and reported strains of different countries are incorporated in tree for genetic evaluation. Selected sequences were aligned by Neighbour-Joining (N) Method. This information provides many important aspects $[2,9,10]$. Topologically, the phylogenetic tree revealed that IBDVs separated into three main groups, namely vvIBD viruses, classic/variant viruses and attenuated/vaccine strains. Very virulent viruses further divided into VV1, VV2 and VV3. While IBDVs that formed VV1 cluster are mostly from this study and reported Pakistani isolates. South African and Nigerian viruses also fall in same clade. VV2 and VV3 clusters incorporate the Europe, Asia and African continent's vvIBDVs. The majority $(11 / 15)$ of the characterized IBDVs from Pakistani strains belonged to the VV1 cluster, and it appeared that these viruses may have been derived from a progenitor of IBDV-PK-1. Pakistani isolates UAF06 and Pak04 lies in atypical category. It falls between classical/variant and attenuated vaccinal groups. New isolates, PAK/129 and PAK/012 aligns in attenuated clade and resembles closely with vaccinal strains. The specimens of later discussed isolates (PAK/129) were collected from field, has history of vaccination in the same week of outbreak. It provides information about wild/field strains, attenuated and strains which were incorporated in field vaccination to control losses of poultry. In field mostly, live vaccines are used to protect the poultry population. There might be genetic modification/mutations in field IBDVs which results in vaccine failure.

Table 3: Detail of sequences of present research and reported isolates used in phylogenetic analysis

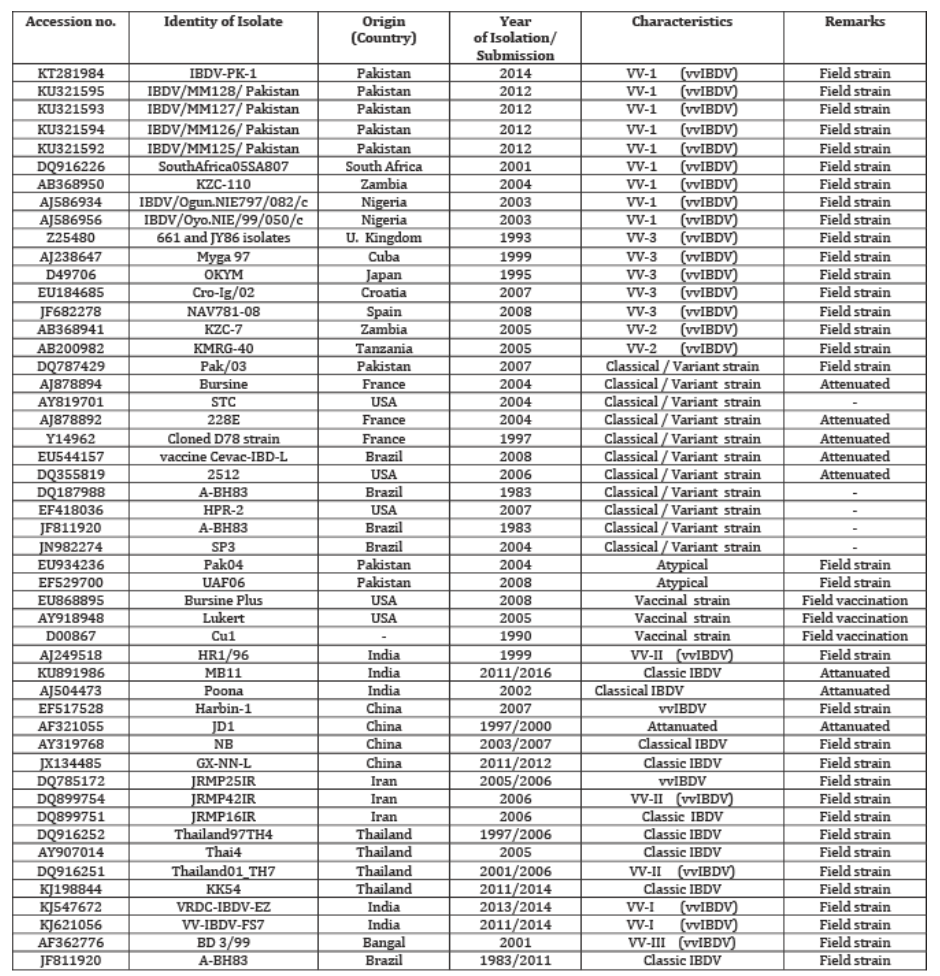

\subsection{Amino acid sequence analysis}

From nucleotide analysis, amino acid sequences were derived for evaluation. In agreement with the predicted amino acid sequences, all of the viruses under study possessed characteristic amino acid residues $222 \mathrm{~A}$, 242I, 256I, 279D, 294I and 299S [30]. Apart from aa change, presence of hepta-peptide is typically observed in vvIBDVs [1]. First five accession numbers representing field isolates in phylogenetic tree has shared $100 \%$ amino acid sequence identity. At position 222 Alanine (A) is replaced by Proline (P) in PAK/012 (reported) and PAK/129 (this study). In attenuated strains (Y14962.1- D78 strain; EU544157.1-IBDV strain vaccine Cevac-IBD$\mathrm{L}$ and DQ355819.1-IBDV strain 2512) replacement of A222P is characteristic. In Pak/03 amino acid 279D and 284T were present which matches with Bursine (AJ878894.1) and Luckert (AY918948.1) strains of commercial vaccines. The exchange of $\mathrm{Q} 253 \mathrm{H}$ and $\mathrm{A} 284 \mathrm{~T}$ were reported in attenuated and tissue culture adopted IBDV in VP2 gene [31]. Single change (A284T) may be responsible for its changing antigenic pattern.

Table 4: Pattern of amino acid (aa) differences among sequences obtained during research. Positions were estimated from first aa of VP2 gene

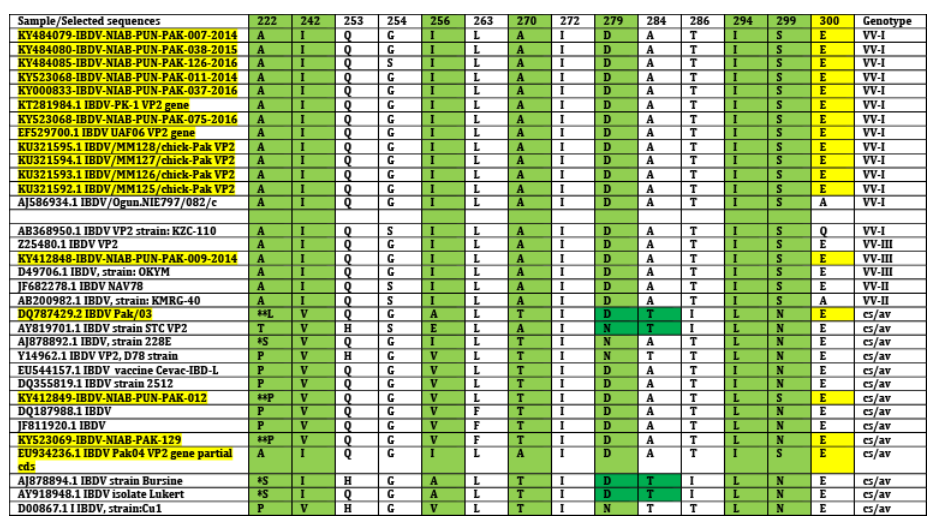


*It shows strains incorporated in Vaccine. ${ }^{* *}$ Pakistani Isolates (amino acid change)

\{Light green background indicates genetic markers of virulence\} Dark green presence of same aa at (279 \& 284) Yellow background indicates presence of aa ' $E$ ' in all Pakistani isolates VV stands for very virulent; cs stands for classical strain ; av stands for antigenic variant.

\section{DISCUSSION}

In present study, it is investigated that outbreaks of IBD were continuously occurring all over the Pakistan. The samples were collected from suspected flocks since 2014. It is assumed that the vaccinated flocks have more protection as compared to non-vaccinated ones but the IBD outburst is equally found in both categories. The research analysis showed that there is wide difference between present circulating IBD viral load and the attenuated viruses, incorporated in commercial vaccines. The study was designed to characterize the existing IBDV strains $[32,33]$ responsible for causing economic losses.

Initially disease pattern was characterized on severity of clinical appearance of birds and PM findings supported with histopathological studies. Both clinical and subclinical IBDV infected birds showed immunosuppression which results in compromising humoral and cellular immune responses [34]. With advancement, restriction enzymes were used as genetic markers to characterize the IBDV. Amplicon of $743 \mathrm{bp}$ was amplified with specific primer [35] and SspI restriction enzyme digestion yielded fragments of approximately $470 \mathrm{bp}$ and $273 \mathrm{bp}$. It verified the utility of the restriction site of this restriction enzyme as a virulence marker. The same studies were reported in previous work [36, 37]. It confirmed the presence of vvIBDV in Pakistan [38]. It is noted that most of Pakistani samples showed resemblance with vvIBDV groups. In selected sequences, the presence of $\mathrm{H} 253 \mathrm{Q}$ and T284A categorized in vvIBDVs while the IBDV types with intermediate virulence have $Q$ and $T$ at these two sites, respectively. Moreover, all avirulent strains have $\mathrm{H}$ and $\mathrm{T}$ at these two sites. These findings also suggest that location 253 plays a more critical role in the virulence of IBDV [39]. Isolates bearing accession numbers KY484080, KY484085, KY523068, KY000833 and KY484079 are closely grouped with already reported sequence, KT281984. The earlier reported putative sequence showed $99 \%$ similarity with the Indian strains. Kataria reported that Indian field isolates found similar to very virulent viruses from European and other Asian countries [40]. At nucleotide level, none of Pakistani samples showed $100 \%$ similarity. Within each group the local strains reflected divergence less than $2 \%$ but intragroup divergence reached up to $8.5 \%$ which may be due to wide temporal and geographical differences of these isolates [8]. The Japanese strain D49706.1 differ 4.2\% from native vvIBDVs. The virulent Nigerian vvIBDVs (African lineage) showed divergence 5.1-5.6\% from Pakistani isolates [41]. European sequences divergence increases but presence of virulent markers showed the common lineages. This study revealed that vvIBDVs displayed divergence up to $10.6 \%$ from vaccinalstrains. The amino acids at P222A, V256I, L294I and N299S are conserved in vvIBDVs of Indian and Pakistani isolates $[2,41]$. The same findings were observed in Senegalese vvIBDVs belonging to African linages. All the Senegalese virulent strains of IBDV had the same amino acid sequences at positions 253 (Q), 279 (D) and 284 (A) as present in the research isolates [42]. The single mutation at $\mathrm{H} 253 \mathrm{Q} / \mathrm{N}$ enhanced the virulence of attenuated strain [43]. The amino acid change at regions, major hydrophilic region ' $\mathrm{A}$ ' and /or ' $\mathrm{B}$ ' have been reported to be important in binding of neutralizing monoclonal antibodies of variant and very virulent groups $[41,44]$. It was discussed earlier that amino acid positions under high selection pressure in peaks A or B, I or II and III may be essential for maintaining VP2 structural conformations responsible for antigenicity, virulence and identity of IBDVs [32].[Fig. 1]

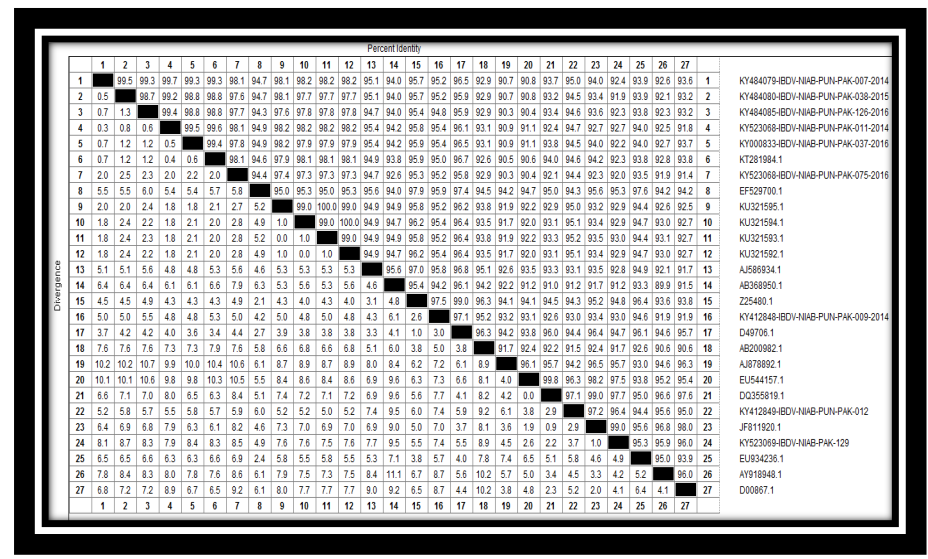

Figure 4: Percent similarity and divergence of nucleotide sequences of hypervariable regions of the isolates from this study with reference to representative strains of different pathotypes of IBDVs, including vaccine strains.

All the selected sequences depicted nucleotide GCA (Alanine) at position 628-630 (210) but Pakistani isolate (KY523068) replaced GGT (Glysine) by changing two bases. It may contribute in the virulence as it is situated close to major hydrophilic region A. In the beginning of region A, N212K amino acid enhanced the virulence of putative isolate. In field outbreak, it shows mortality up to $18 \%$ than other indigenous samples. In recent years amino acid change $\mathrm{D} 212 \mathrm{~N}$ found in the same hydrophilic region ' $\mathrm{A}$ ', may also be essential in structural stability of the hypervariable region, VP2 protein [30]. The trend of mutation is followed naturally in the existing genetic pool of Indo-Pak region [8]. Some of US variant and French vvIBDVs matched the similar ongoing change $[9,41]$. Shabir and co-workers reported that Histidine, amino acid (H) is located at position 221 [33] is characteristic for Pakistani strains. Present studies differ from reported information. The virulence marker 222 showed major difference among very virulent, classical/variant and vaccinal strains [32, 45]. In all Pakistani reported isolates, amino acid (aa) Glutamic acid (E) is located at position 300 in minor hydrophilic region III whereas neighboring aa N299S change significantly play its role in virulence of vvIBDVs. It's reported that each country showed resemblance within existing aa change at hydrophilic region III for subtyping i-e classical, variant and vvIBDVs. The change in the minor region I and II were more significant for subtyping of strains rather than complete hypervariable region of VP2 gene [32].

It's very interesting that all the outbreaks were identified in the vaccinated flocks irrespective of broiler or layer farming. Usually virulent classical viruses, genetically related to current attenuated classical vaccine strains were incorporated in the field available vaccines [46-49].

Samples having IDs i-e PAK/129 (this study), PAK/012 (this study), Pak04 (reported), UAF06 (reported) and Pak/03 (reported) were closely matched in classical and variant groups. The slight change in virulence markers may result in vaccine failure [50] . At positions S222P/L/A and N279D, amino acid alterations may be responsible for vaccine failure. PAK/129, isolate showed 99\% similarity with Brazilian sequence. Vaccines are being imported from Brazil. The history of flock shows that outbreak of disease occurs after vaccination with intermediate plus strain. It may be vaccine failure due to slight mutation in vaccine strains. It requires more study with supporting evidences to conclude the final fate. For designing IBD vaccine, the above said changes should be considered in planning and manufacturing at local level. PAK/012, sample resembles with Thailand's sequence derived from commercial poultry farm in 2011. Its resemblance was $97 \%$ with both Thailand and Brazilian isolates. Geographically Thailand is situated next to China in Asian continent. These wild strains are responsible for field outbreaks in common business engaged regions [51].

The serine-rich heptapeptide sequence 'SWSASGS' adjacent to the second major hydrophilic region was indicative of vvIBD viruses [1]. This conserve region may be part of vaccinal and attenuated viruses but changes at other virulence markers play key role in immunogenicity [52, 53]. In current studies, the minute substitution, N279D and T284A indicate that the field IBD viruses are not attenuated or adaptation of virus to cell culture. In phylogenetic tree isolates bearing IDs UAF06 and Pak04 are falling close to attenuated strains which may shows the intermediate existence between the classical and attenuated isolates. Pak/03 has aa N279D and A284T change which is similar to Bursine stain and Luckert isolate. Leucine (L) to Serine (S) amino acid change is noted in the same sample [31]. Remaining amino acid alterations were mostly conservative in nature [54-57]. The changes in the hydrophilic regions of the VP2 protein were important as they are indicative of continuous changes going on in viral genome [58-62]

\section{CONCLUSION}

On the Basis of chronology, the occurrence of disease is due to vvIBDV isolates in Asia and neighboring continents. Phylogenetic relationship points out that most of the Pakistani IBDVs genetically similar to reported very virulent IBDV Indian strains. It's reported earlier that Bangladeshi vvIBDV strains (E300A) penetrates to India. Pakistan shares border with India and Afghanistan geographically. China and Iran measures small boundaries whereas remaining areal part exposed to Arabian Sea. Poultry Industry in Afghanistan is not developed due to unstable socio-economic environment. Poultry farming areas were present along with the boundary of India. Its poultry industry is competing internationally. The aerosol transmission and the role of migratory animals, worms and birds are well documented. 


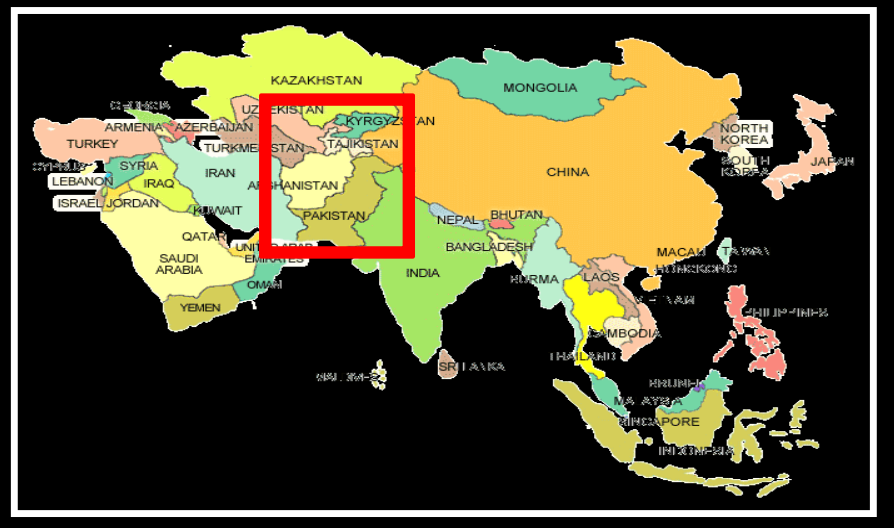

Figure 5: Map of Asia Continent showing border sharing countries of Pakistan. (Source Google Images)

Furthermore, complete information reported on isolates and classical viruses will provide more information of virus characteristics and mode of transmission. Common strategies to control the circulating vvIBDV with border sharing countries will reduce the financial losses of poultry farms of both countries. Therefore, for better coverage, development of a vaccine from local or regional IBDV field strains is in the favor of Pakistan and neighboring countries for controlling IBD.

\section{REFERENCES}

[1] Morla, S., Deka, P., and Kumar, S. 2016. Isolation of novel variants of infectious bursal disease virus from different outbreaks in Northeast India. Microbial pathogenesis, 93, 131-136.

[2] Cao, Y., Yeung, W., Law, M., Bi, Y., Leung, F., and Lim, B. 1998. Molecular characterization of seven Chinese isolates of infectious bursal disease virus: classical, very virulent, and variant strains. Avian diseases, 340-351.

[3] Vervelde, L., and Davison, T. 1997. Comparison of the in-situ changes in lymphoid cells during infection with infectious bursal disease virus in chickens of different ages. Avian Pathology, 26, 803-821.

[4] Tamura, K., Peterson, D., Peterson, N., Stecher, G., Nei, M., and Kumar, S 2011. MEGA5: molecular evolutionary genetics analysis using maximum likelihood, evolutionary distance, and maximum parsimony methods. Molecular biology and evolution, 28, 2731-2739.

[5] Qureshi, A. 1999. FEATURES-Gumboro Disease in Pakistan First diagnosed in 1971, this disease has now become widespread. Poultry International, 38, 42-43.

[6] Khan, K., Shah, S., and Afzal, M. 1988. Observations on Gumboro disease (infectious bursal disease) in Pakistan. Revue Scientifique et Technique de l'OIE (France).

[7] Khan, R. S. A., Sajid, S., Habib, M., Ali, W., Shah, M. S.-u.-D., and Sarfraz, M. 2017. History of Gumboro (infectious bursal disease) in Pakistan. Saudi Pharmaceutical Journal: SPJ. 25, 453.

[8] Kataria, R., Tiwari, A., Butchaiah, G., Kataria, J., and Skinner, M. 2001. Sequence analysis of the VP2 gene hypervariable region of infectious bursal disease viruses from India. Avian Pathology, 30, 501-507.

[9] Dormitorio, T., Giambrone, J., and Duck, L. 1997. Sequence comparisons of the variable VP2 region of eight infectious bursal disease virus isolates. Avian diseases, 36-44.

[10] Brown, M. D., Green, P., and Skinner, M. A. 1994. VP2 sequences of recent European 'very virulent'isolates of infectious bursal disease virus are closely related to each other but are distinct from those of 'classical'strains. Journal of General Virology, 75, 675-680.

[11] Van den Berg, T., Morales, D., Eterradossi, N., Rivallan, G., Toquin, D., Raue, R. 2004. Assessment of genetic, antigenic and pathotypic criteria for the characterization of IBDV strains. Avian Pathology, 33, 470-476.

[12] Durairaj, V., Sellers, H. S., Linnemann, E. G., Icard, A. H., and Mundt, E. 2011. Investigation of the antigenic evolution of field isolates using the reverse genetics system of infectious bursal disease virus (IBDV). Archives of virology, 156, 1717-1728.

[13] Schnitzler, D., Bernstein, F., Müller, H., and Becht, H. 1993. The genetic basis for the antigenicity of the VP2 protein of he infectious bursal disease virus. Journal of General Virology, 74, 1563-1571.

[14] Letzel, T., Coulibaly, F., Rey, F. A., Delmas, B., Jagt, E., Van Loon, A. A 2007. Molecular and structural bases for the antigenicity of VP2 of infectious bursal disease virus. Journal of virology, 81, 12827-12835.

[15] Jackwood, D. J., Saif, Y. M., and Hughes, J. H. 1982. Characteristics and serologic studies of two serotypes of infectious bursal disease virus in turkeys. Avian diseases, 871-882.

[16] Chettle, N., Stuart, J., and Wyeth, P. 1989. Outbreak of virulent infectious bursal disease in East Anglia, Veterinary Record, 125, 271-272.

[17] Sapats, S., and Ignjatovic, J. 2000. Antigenic and sequence heterogeneity of infectious bursal disease virus strains isolated in Australia. Archives of virology, 145, 773-785

[18] Bayliss, C., Spies, U., Shaw, K., Peters, R., Papageorgiou, A., Müller, H. 1990. A comparison of the sequences of segment A of four infectious bursal disease virus strains and identification of a variable region in VP2. Journal of General Virology, 71, 1303-1312.

[19] Zierenberg, K., Nieper, H., Van den Berg, T., Ezeokoli, C., Voss, M., and Müller, H. 2000. The VP2 variable region of African and German isolates of infectious bursal disease virus: comparison with very virulent,"classical" virulent, and attenuated tissue culture-adapted strains. Archives of Virology, $145,113-125$.

[20] Sah, R., Kataria, J., Arya, S., and Verma, K. 1995. Outbreaks of acute infectious bursal disease causing high mortality in chicken. Indian Journal of Comparative Microbiology Immunology and Infectious Diseases, 16, 7-13.

[21] Washington, J. A. 2012. Laboratory procedures in clinical microbiology: Springer Science and Business Media.

[22] Jackwood, D., Hanes, G., and Miller, S. H. 1996. Infectious bursal disease viral RNA amplification using RT/PCR from bursa tissue following phenol: chloroform inactivation of the virus, Avian diseases, 457-460.

[23] Jackwood, D. J. 2012. Molecular epidemiologic evidence of homologous recombination in infectious bursal disease viruses. Avian diseases, 56, 574-577.

[24] Tamura, K., Stecher, G., Peterson, D., Filipski, A., and Kumar, S. 2013 MEGA6: molecular evolutionary genetics analysis version 6.0. Molecular biology and evolution, 30, 2725-2729.

[25] Kimura, M. 1980. A simple method for estimating evolutionary rates of base substitutions through comparative studies of nucleotide sequences. Journal of molecular evolution, 16, 111-120.

\section{[26] Pattison, M. 2008. Poultry diseases: Elsevier Health Sciences.}

[27] Shekaro, A., and Josiah, I. 2015. Infectious bursal disease outbreak in fifteen weeks old pullets in Kaduna, Nigeria. Journal of Animal Production Advances, 5, 636-644.

[28] Mohabe, L. K. 2012. Studies on prevalence, pathology and molecular diagnosis of infectious bursal disease in broilers. Chhattisgarh Kamdhenu Vishwavidyalaya, Durg.

[29] Le Nouën, C., Toquin, D., Müller, H., Raue, R., Kean, K. M., Langlois, P. 2012. Different domains of the RNA polymerase of infectious bursal disease virus contribute to virulence. PloS one, 7, e28064.

[30] Yuwen, Y., Gao, Y., Gao, H., Qi, X., Li, T., Liu, W. 2008. Sequence analysis of the VP2 hypervariable region of eight very virulent infectious bursal disease virus isolates from the northeast of China. Avian diseases, 52 284-290.

[31] Van Loon, A., De Haas, N., Zeyda, I., and Mundt, E. 2002. Alteration of amino acids in VP2 of very virulent infectious bursal disease virus results in tissue culture adaptation and attenuation in chickens. Journal of General Virology, 83, 121-129.

[32] Adamu, J., Owoade, A., Abdu, P., Kazeem, H., and Fatihu, M. 2013. Characterization of field and vaccine infectious bursal disease viruses from Nigeria revealing possible virulence and regional markers in the VP2 minor hydrophilic peaks. Avian Pathology, 42, 420-433.

[33] Shabbir, M. Z., Ali, M., Abbas, M., Chaudhry, U. N., and Munir, M. 2016 Molecular characterization of infectious bursal disease viruses from Pakistan. Archives of virology, 161, 2001-2006. 
[34] Sharma, J. M., Kim, I.J., Rautenschlein, S., and Yeh, H.Y. 2000. Infectious bursal disease virus of chickens: pathogenesis and immunosuppression. Developmental and Comparative Immunology, 24, 223-235.

[35] Jackwood, D., and Sommer, S. 1999. Restriction fragment length polymorphisms in the VP2 gene of infectious bursal disease viruses from outside the United States. Avian diseases, 310-314.

[36] Abdel-Alim, G. A., Awaad, M. H. H., and Saif, Y. 2003. Characterization of Egyptian field strains of infectious bursal disease virus. Avian diseases, 47, 1452-1457.

[37] Ture, O., Saif, Y., and Jackwood, D. 1998. Restriction fragment length polymorphism analysis of highly virulent strains of infectious bursal disease viruses from Holland, Turkey, and Taiwan. Avian diseases, 470-479.

[38] Zahoor, M., Hussain, I., and Khan, Q. 2005. Two outbreaks of very virulent infectious bursal disease virus in Pakistan. Veterinary record, 157, 813.

[39] Li, Z., Qi, X., Ren, X., Cui, L., Wang, X., and Zhu, P. 2015. Molecular characteristics and evolutionary analysis of a very virulent infectious bursal disease virus, Science China. Life Sciences, 58, 731.

[40] Kataria, R., Tiwari, A., Butchaiah, G., and Kataria, J. 1999. Differentiation of infectious bursal disease virus strains by restriction analysis of RT-PCRamplified VP2 gene sequences. Acta virologica, 43, 245-249.

[41] Eterradossi, N., Arnauld, C., Tekaia, F., Toquin, D., Le Coq, H., and Rivallan, G. 1999. Antigenic and genetic relationships between European very virulent infectious bursal disease viruses and an early West African isolate. Avian Pathology, 28, 36-46.

[42] Badji, A., Ducatez, M., Lo, F. T., Mbengue, M., Diouf, M., Samb, Y. 2016. Genetic evolution of infectious bursal disease virus in Senegal. Journal of Veterinary Medicine and Animal Health, 8, 237-243.

[43] Jackwood, D., Sreedevi, B., LeFever, L., and Sommer-Wagner, S. 2008. Studies on naturally occurring infectious bursal disease viruses suggest that a single amino acid substitution at position 253 in VP2 increases pathogenicity. Virology, 377, 110-116.

[44] Heine, H.G., Haritou, M., Failla, P., Fahey, K., and Azad, A. 1991. Sequence analysis and expression of the host-protective immunogen VP2 of a variant strain of infectious bursal disease virus which can circumvent vaccination with standard type I strains. Journal of General Virology, 72, 1835-1843.

[45] Silva, F. M., Vidigal, P. M., Myrrha, L. W., Fietto, J. L., Silva, A., and Almeida, M. R. 2013. Tracking the molecular epidemiology of Brazilian Infectious bursal disease virus (IBDV) isolates. Infection, Genetics and Evolution, 13, 18-26.

[46] Cardoso, T. C., Rosa, A. C., Astolphi, R. D., Vincente, R. M., Novais, J. B., Hirata, K. Y. 2008. Direct detection of infectious bursal disease virus from clinical samples by in situ reverse transcriptase-linked polymerase chain reaction. Avian Pathology, 37, 457-461.

[47] Jenberie, S., Lynch, S. E., Kebede, F., Christley, R. M., Gelaye, E., Negussie, H. 2014. Genetic characterization of infectious bursal disease virus isolates in Ethiopia. Acta tropica, 130,39-43

[48] Lojkić, I., Bidin, Z., and Pokrić, B. 2008. Sequence analysis of both genome segments of three Croatian infectious bursal disease field viruses. Avian diseases, 52, 513-519.
[49] Martin, A. M., Fallacara, F., Barbieri, I., Tosi, G., Rivallan, G., Eterradossi, N. 2007. Genetic and antigenic characterization of infectious bursal disease viruses isolated in Italy during the period 2002-2005. Avian diseases, 51, 863-872.

[50] Van den Berg, T., Eterradossi, N., Toquin, D., and Meulemans, G. 2000. Infectious bursal disease (Gumboro disease). Revue scientifique et technique (International Office of Epizootics), 19, 509-543.

[51] Ndashe, K., Simulundu, E., Hang'ombe, B. M., Moonga, L., Ogawa, H., Takada, A. 2016. Molecular characterization of infectious bursal disease viruses detected in vaccinated commercial broiler flocks in Lusaka, Zambia. Archives of virology, 161, 513-519.

[52] Lim, B.L., Cao, Y., Yu, T., and Mo, C.W. 1999. Adaptation of very virulent infectious bursal disease virus to chicken embryonic fibroblasts by sitedirected mutagenesis of residues 279 and 284 of viral coat protein VP2. Journal of Virology, 73, 2854-2862.

[53] Yamaguchi, T., Ogawa, M., Inoshima, Y., Miyoshi, M., Fukushi, H., and Hirai, K. 1996. Identification of sequence changes responsible for the attenuation of highly virulent infectious bursal disease virus. Virology, 223, 219-223.

[54] Le Nouen, C., Rivallan, G., Toquin, D., Darlu, P., Morin, Y., Beven, V. 2006. Very virulent infectious bursal disease virus: reduced pathogenicity in a rare natural segment-B-reasserted isolate. Journal of general virology, 87, 209-216.

[55] Mohamed, M. A., Elzanaty, K. E., Bakhit, B. M., and Safwat, M. M. 2014 Genetic Characterization of Infectious Bursal Disease Viruses Associated with Gumboro Outbreaks in Commercial Broilers from Asyut Province, Egypt, ISRN veterinary science.

[56] Khan, A., and Yusof, Z. 2017. Trade-Terrorist Evaluation Index (TTEi). Quality and Quantity, 51, 365-375.

[57] Mehta, R., Nambiar, R., and Joshi, P. 2016. India's Poultry Sector: Trade Prospects, International Trade and Food Security. The Future of Indian Agriculture, 115

[58] Zhao, Y., Aarnink, A. J., Cambra-Lopez, M., and Fabri, T. 2013. Viral shedding and emission of airborne infectious bursal disease virus from a broiler room. British poultry science, 54, 87-95.

[59] Chan, J. F.W., To, K. K.W., Chen, H., and Yuen, K.Y. 2015. Cross-species transmission and emergence of novel viruses from birds. Current opinion in virology, 10, 63-69.

[60] Lee, D.H., Torchetti, M. K., Winker, K., Ip, H. S., Song, C.S., and Swayne, D. E. 2015. Intercontinental spread of Asian-origin H5N8 to North America through Beringia by migratory birds. Journal of virology, 89, 6521-6524.

[61] Wang, Y., Wang, Z., Tang, Y., Shi, Z., He, K., Li, Y. 2007. Comparison of four infectious bursal disease viruses isolated from different bird species. Archives of virology, 152, 1787-1797.

[62] Priyadharsini, C., Senthilkumar, T., Raja, P., and Kumanan, K. 2016. Genotypic characterization of Indian isolates of infectious bursal disease virus strains by reverse transcription-polymerase chain reaction combined with restriction fragment length polymorphism analysis. Acta virologica, 60 34-40. 